\title{
Multiple Sclerosis Databases: Present and Future
}

\author{
Peter Flachenecker \\ Neurological Rehabilitation Center, Quellenhof, Bad Wildbad, Germany
}

\section{Key Words}

EUReMS · Multiple sclerosis · Registries

\section{Introduction}

The aim of this presentation is to increase understanding of the need for multiple sclerosis (MS) registries, update the status on some national registries set up across Europe (including the German MS registry) and provide an update on a pan-European initiative to create a 'European registry' which is the core of the European Register for Multiple Sclerosis (EUReMS) project.

\section{Why do we Need Registries?}

MS registries and databases are useful platforms for monitoring large patient populations and are valuable tools for studying epidemiological trends, disease characteristics and long-term outcomes in everyday clinical practice. In other words, systematic collection of patient information can be used to develop standardized levels of data collection and recording which can drive best practice and improvements in patient care based on real-life findings from large patient populations.

MS registries can provide information relating to healthcare systems and the provision of treatment and services, as well as their associated impact on overall health and level of disability in the MS patient population. Such data can be used to compare the benefits of different types and levels of healthcare, both within and between regions and countries. For this purpose, the MS Barometer was created by the European MS Platform (EMSP). The Barometer was based on a questionnaire survey conducted in individual countries covering topics such as access to treatment, research agenda, employment, available medications, and more. The results indicated a huge disparity in the provision of MS services across different regions. Countries scoring well were Austria, Germany, Ireland and Sweden among others, while those scoring poorly included Belarus, Bosnia-Herzegovina and Bulgaria. As an example, the percentage of MS patients receiving disease-modifying therapy varied widely, from $80 \%$ in Luxembourg to just $7 \%$ in Poland. In an ideal world, healthcare providers in countries scoring poorly on the Barometer with respect

\section{KARGER}

E-Mail karger@karger.com www.karger.com/ene
Dr. P. Flachenecker

Neurological Rehabilitation Center, Quellenhof Kuranlagenallee 2

DE-75323 Bad Wildbad (Germany)

E-Mail peter.flachenecker@sana.de 
Box 1. EUReMS Missions

1 To undertake MS epidemiological and clinical surveillance across European countries, including assessment of the 'MS burden'.

2 To assess the long-term efficacy, safety and costeffectiveness of MS disease-modifying and symptomatic treatments across European countries.

3 To assess the provision and quality of healthcare services across European countries.

4 To assess, from the patient's perspective, quality of life and burden of symptoms, including socio-economic aspects, across European countries. and includes 12,000 MS patients), the Italian MS database network (1996 and >20,000 MS patients), the North American Research Consortium on Multiple Sclerosis (NARCOMS) registry (1996 and >30,000 MS patients), and the German MS registry. The German registry was set up in 2001 and is run by the German MS Society. This registry collects epidemiological data (e.g. numbers of patients, disease course, and disability status) and healthcare research details such as numbers of patients receiving immunomodulatory and symptomatic treatments and physiotherapy, as well as information about the provision of MS patient services. There are currently 143 MS centers in Germany; >35,000 patients have been enrolled in the registry and $>93,000$ data sets are available.

\section{EUReMS - A European Register for Multiple Sclerosis}

The EUReMS project (www.eurems.eu) aims to establish a Europe-wide platform for systematic analysis of longitudinally-collected MS data in Europe. EUReMS was set up in 2010 by an international consortium and is co-funded by the European public health program involving both scientists and patient organizations. One of the principles of EUReMS is to build on existing national or regional MS registries and databases. After defining the EUReMS vision and mission (Box 1), a survey was sent to leaders of MS registries currently in use in Europe to obtain information on content and structure. Using this approach, 20 registries were identified which differed widely in their objectives, structure and type of data collected. Whereas physician-based outcome measures are used in all registries, data collected from MS patients themselves are less frequent. Three pilot studies examining epidemiology, long-term outcome of immunotherapies and patient-reported outcomes in MS are ongoing within the framework of the EUReMS project. These studies will test the feasibility of merging and analyzing data from the various national registries under a single umbrella and, in this manner, may answer research questions that could only be solved with studies involving large numbers of patients.

\section{Conclusions}

MS registries are essential tools to provide long-term and large-scale data relating to epidemiological trends, effectiveness of long-term treatments, and an overview of
Flachenecker 
the healthcare situation for MS patients. MS registries at a national level are increasingly being implemented in Europe. Following on from a survey of published MS registries, the EUReMS project now aims to merge and compare registry data to facilitate a harmonized data collection approach across Europe. The EUReMS project is ongoing and first results are expected in late 2014.

\section{Disclosures/Conflict of Interest}

PF has received speaker fees and honoraria from Almirall, Bayer Schering, Biogen Idec, Merck Serono, Novartis and Sanofi; research grants from Bayer Schering, Merck Serono and Sanofi.

Writing assistance was provided by Content Ed Net (Madrid, Spain), with funding from Laboratorios Almirall, SA (Barcelona, Spain). 